\title{
Improving renal phenotype and evolving extra-renal features of $17 q 12$ deletion encompassing the HNF1B gene
}

\author{
Roxana Cleper $^{1,2}$, Adi Reches ${ }^{2,3}$, Dana Shapira ${ }^{1,2}$, Sharon Simchoni ${ }^{3}$, Lewis Reisman ${ }^{1}$, Liat Ben-Sira ${ }^{2,4}$, \\ Yuval Yaron $^{2,3}$, Igal Wolman ${ }^{2,5}$, Gustavo Malinger ${ }^{2,5}$, Dana Brabbing-Goldstein ${ }^{3}$, Shay Ben-Shachar ${ }^{2}$ \\ ${ }^{1}$ Pediatric Nephrology Unit, Dana-Dwek Children's Hospital, Tel Aviv Sourasky Medical Center, Tel Aviv, Israel; 'Sackler Faculty of Medicine, Tel \\ Aviv University, Tel Aviv, Israel; ${ }^{3}$ Prenatal Genetic Diagnosis Unit, Genetic Institute, Tel Aviv Sourasky Medical Center, Tel Aviv, Israel; ${ }^{4}$ Pediatric \\ Radiology Unit, Dana-Dwek Children's Hospital, Tel Aviv Sourasky Medical Center, Tel Aviv, Israel; ${ }^{5}$ Ultrasound Unit in Obstetrics and Gynecology, \\ Lis Maternity Hospital, Tel Aviv Sourasky Medical Center, Tel Aviv, Israel \\ Contributions: (I) Conception and design: R Cleper, S Ben-Shachar; (II) Administrative support: L Ben-Sira, Y Yaron, G Malinger; (III) Provision of study \\ materials or patients: R Cleper, A Reches, D Shapira, S Simchoni, L Ben-Sira, Y Yaron, I Wolman, G Malinger, D Brabbing-Goldstein, S Ben-Shachar; \\ (IV) Collection and assembly of data: R Cleper, L Reisman, D Brabbing-Goldstein, S Ben-Shachar; (V) Data analysis and interpretation: R Cleper, \\ L Reisman, D Brabbing-Goldstein, S Ben-Shachar; (VI) Manuscript writing: All authors; (VII) Final approval of manuscript: All authors. \\ Correspondence to: Dr. Roxana Cleper, MD. Pediatric Nephrology Unit, Dana Dwek Children's Hospital, Tel Aviv Sourasky Medical Center, \\ Tel Aviv 6423914, Israel. Email: roxanac@tlvmc.gov.il.
}

Background: $H N F 1 B$ deletion/intragenic mutations are the most commonly identified genetic cause of congenital anomalies of the kidney and urinary tract (CAKUT) suggested by fetal ultrasound findings such as: parenchymal hyperechogenicity, overt cystic changes or gross morphological urinary system (UT) abnormalities. The postnatal evolution of these $17 \mathrm{q} 12$ deletions encompassing the $H N F 1 B$ gene-associated findings has not been assessed in depth.

Methods: In this observational study, we present postnatal follow-up findings in 5 of 6 cases (one pregnancy was terminated on parental request) of fetal-onset cystic/hyperechogenic kidneys eventually diagnosed with 17 q12 microdeletion encompassing the HNF1B gene between 2009 and 2017.

Results: Complete normalization of kidney parenchymal abnormalities and of depressed neonatal renal function was observed in $4 / 5$ and 5/5 patients within 2-4.9 years and 1.5-8 months, respectively. All 5 patients had preserved normal renal function at 3-11 years of follow-up. The evolving later-onset renal features included: hypomagnesemia, hyperuricemia, urinary tract infection (UTI), and bilateral grade 3-4 vesicoureteral reflux and bladder diverticula in 3, 3, 2, and 1 patient, respectively. HNF1B gene deletionassociated extra-renal manifestations with delayed presentation were global developmental delay/autistic spectrum disorder (ASD), rolandic-type seizures, overweight, and borderline fasting hyperglycemia observed in 1-2 patients each. Family history was positive for small-size or asymptomatic cystic kidneys with normal function, diabetes mellitus, seizures, and mental/psychiatric problems in 3/6 cases.

Conclusions: Fetal-onset HNF1B deletion-associated kidneys' parenchymal abnormalities confirmed postnatally with initially depressed renal function might undergo complete resolution within several years and few months, respectively. However, later-onset urinary tract, metabolic, and neurodevelopmental features of this mutation might appear over years. Therefore, genetic molecular evaluation/diagnosis and continuous follow-up for evolving features are mandatory in affected children.

Keywords: $17 \mathrm{q} 12$ deletion; HNF1B gene; hyperechogenic kidneys; congenital anomalies of the kidney and urinary tract (CAKUT); hypomagnesemia

$\wedge$ ORCID: 0000-0003-2721-5004. 
Submitted Aug 14, 2021. Accepted for publication Nov 01, 2021.

doi: $10.21037 /$ tp-21-386

View this article at: https://dx.doi.org/10.21037/tp-21-386

\section{Introduction}

Hyperechogenicity of fetal kidney parenchyma might be normal during certain stages of nephrogenesis but at other times suggestive of congenital anomalies of the kidney and urinary tract (CAKUT) or genetic cystic kidney disease, such as autosomal dominant polycystic kidney disease (ADPKD), autosomal recessive polycystic kidney disease (ARPKD), nephronophthisis/medullary cystic disease complex, overgrowth syndromes, and congenital nephrotic syndrome (1-4). The past 2 decades have witnessed the identification of more than 40 genes critically involved in nephrogenesis and more than 95 genes associated with cystic kidney disease (5-8). Indeed, causative mutations in one of these genes have been identified in up to $17-20 \%$ of CAKUT and $50-70 \%$ of cystic (hyperechogenic) kidneys in pediatric (including fetal) cohorts (2,7-10). Among these, $H N F 1 B$ deletion/intragenic mutations are the ones most commonly identified (2,6-12).

$H N F 1 B$ is a transcription factor that regulates expression of multiple genes crucial to morphogenesis of the kidneys, genitalia, pancreas, liver, thymus, and gut (8,9,13-16) $H N F 1 B$ loss-of-function mutations were first described as the etiological cause of renal cysts and diabetes (MODY5 type) syndrome (RCAD) $(8,9,13-15)$.

$H N F 1 B$ nephropathy refers to the wide spectrum of renal abnormalities induced by microdeletions at the $17 \mathrm{q} 12$ locus. It extends from renal parenchymal hyperechogenicity due to microcystic dysplasia through overt cystic changes and up to different types of CAKUT, among which multicystic dysplastic kidney (MCDK) and unilateral renal agenesis (URA) are the most prominent (10,13,15-21). Variable onsets of extra-renal manifestations of this genetic abnormality have also been described (13-16). The postnatal renal and extra-renal courses in cases of $H N F 1 B$-associated fetal sonographic abnormalities remain unclear.

We present our experience with 6 cases, including one aborted fetus and 5 patients who were followed in our clinic subsequent to prenatal diagnosis of abnormal fetal renal parenchyma and who were eventually diagnosed with $H N F 1 B$ microdeletion. These descriptions highlight previously unreported features of the evolving phenotypic spectrum in patients carrying this mutation.

We present the following article in accordance with
STROBE reporting checklist (available at https://dx.doi. org/10.21037/tp-21-386).

\section{Methods}

\section{Study population}

Patients and fetuses identified as carrying the $H N F 1 B$ microdeletion in our institute during 2009-2017.

\section{Sample collection and work-up}

The chromosomal microarray analysis (CMA) that was performed in all patients and fetuses employed DNA from amniotic fluid prenatally as well as DNA extracted from blood postnatally. CMA was performed with the CytoScan $750 \mathrm{~K}$ array (Affymetrix, Santa Clara, CA, USA), which is composed of 550,000 nonpolymorphic copy number variant probes and more than 200,000 single-nucleotide polymorphism probes, with an average resolution of $100 \mathrm{~Kb}$. Analysis was performed with ChAS software from Affymetrix. Genomic coordinates were evaluated in accordance with genome build GRCh37/hg19. Analyses were according to the standards and guidelines of the American College of Genetics and Genomics for constitutional cytogenomic microarray analysis. Clinical prenatal and postnatal data including latest follow-up of the study cohort were recorded and analyzed. Fetal and postnatal kidney sonographic echogenicity was defined as normal or hyperechogenic by comparison to adjacent liver and/or spleen texture according to accepted age-adjusted standards $(4-7,22)$.

\section{Statistical analysis}

The small number of participants in this cohort study precluded formal statistical analysis.

\section{Ethical statement}

The study was conducted in accordance with the Declaration of Helsinki (as revised in 2013) and was approved by the Institutional Ethics Review Board of Tel Aviv Sourasky Medical Center Hospital (registration No. 0498-14-TLV), and individual consent for this 
Table 1 Clinical, genetic and follow-up data of study cohort with 17q12 deletion encompassing the HNF1B gene

\begin{tabular}{|c|c|c|c|c|c|c|}
\hline Patient No. & 1 & 2 & 3 & 4 & 5 & 6 \\
\hline \multicolumn{7}{|l|}{ Diagnosis } \\
\hline Phenotype & Seizures, $S_{\mathrm{Mg}} \downarrow$ & Cystic kidneys & Cystic kidneys & ASD & ASD & $\begin{array}{l}\text { SFK + cyst } \\
\text { (S/PMCDK), } S_{M g} \downarrow\end{array}$ \\
\hline Family & ASD, seizures & $\begin{array}{l}\text { Father-MODY + } \\
\text { small kidneys - }\end{array}$ & Normal & Normal & Normal & \\
\hline \multicolumn{7}{|l|}{ Fetal $^{\dagger}$ imaging } \\
\hline MRI & NP & $\begin{array}{l}\text { ABN signal (B), } \\
\text { size } \downarrow(U), \text { cysts }(U)\end{array}$ & $\begin{array}{l}\text { ABN signal }(B) \\
\text { cysts }(B), \text { size } \uparrow(B)\end{array}$ & $\begin{array}{l}\text { ABN signal }(B)^{\dagger \dagger \dagger} \\
\text { UTD }(U), \text { size } \downarrow(U)\end{array}$ & $\begin{array}{l}\text { ABN signal }(B), \\
\text { size-N (B) }\end{array}$ & NP \\
\hline \multicolumn{7}{|l|}{ Postnatal } \\
\hline US $(K+U T)$ & $\mathrm{HE}(\mathrm{B}) \rightarrow \mathrm{N}$ (24 months) & TOP & $\begin{array}{l}\text { HE + cysts (B), } \\
\text { size } \uparrow(B), \text { UTD }\end{array}$ & $\begin{array}{l}\mathrm{HE}(\mathrm{B}) \rightarrow \mathrm{N} \\
36 \text { months, size- } \\
\mathrm{LN}\end{array}$ & $\begin{array}{l}\mathrm{HE}(\mathrm{B}) \rightarrow \mathrm{N} \\
36 \text { months, size- } \\
\mathrm{LN}\end{array}$ & $\begin{array}{l}\mathrm{HE}(\mathrm{U}), \mathrm{MCDK}- \\
\varnothing 4.9 \text { years }\end{array}$ \\
\hline Scr & $\uparrow \rightarrow \mathrm{N}$ (1.5 months) & & $\uparrow \rightarrow \mathrm{N}$ (1.5 months) & $\uparrow \rightarrow \mathrm{N} 19$ days & $\uparrow \rightarrow \mathrm{N} 19$ days & $\uparrow \rightarrow \mathrm{N}$ (8 months) \\
\hline Last f/u & Age 6 years & TOP & Age 6 years & Age 3 years & Age 3 years & Age 11.5 years \\
\hline
\end{tabular}

*, monochorionic disconcordant twins-Pt 4-smaller twin, IUGR; ${ }^{* *}$, maternally inherited, normal maternal phenotype; ${ }^{* *}$, see text Patient 6; ${ }^{\dagger}$, kidney size and AFV normal if not stated otherwise; ${ }^{\dagger \dagger}$, kidney's hyperechogenicy more pronounced in smaller twin-Patient 4 than in larger twin-Patient 5; ${ }^{\mathrm{tt}}$, abnormal parenchymal signal on fetal MRI more pronounced than in twin-Patient 5; CMA+, positive for HNF1B deletion mutation, CMA-, negative for HNF1B deletion mutation. $\mathrm{S}_{\mathrm{Mg}}$, serum magnesium; ASD, autistic spectrum disorder; SFK, solitary functioning kidney; GW, gestational week; MODY, maturity-onset diabetes mellitus of young; CMA, chromosomal microarray analysis; NP, not performed; HE, hyperechogenic kidney parenchyma; B, bilateral; U, unilateral; MCDK, multicystic dysplastic kidney; UTD, urinary tract dilatation; N, normal; LN, low normal; TOP, termination of pregnancy; Scr, serum creatinine; f/u, follow-up; SUa, serum uric acid; BMI, body mass index; LE, liver enzymes; AFV, amniotic fluid volume.

retrospective analysis was waived.

\section{Results}

\section{Patient characteristics}

Main findings presented in Table 1.

\section{Patient 1}

Patient 1 was a 4.5-year-old normally developed girl who presented with a partial tonic-clonic seizure disorder. The clinical examination disclosed no dysmorphic features, cutaneous stigmata, or neurological deficits. Her blood test results revealed hypomagnesemia (serum magnesium 

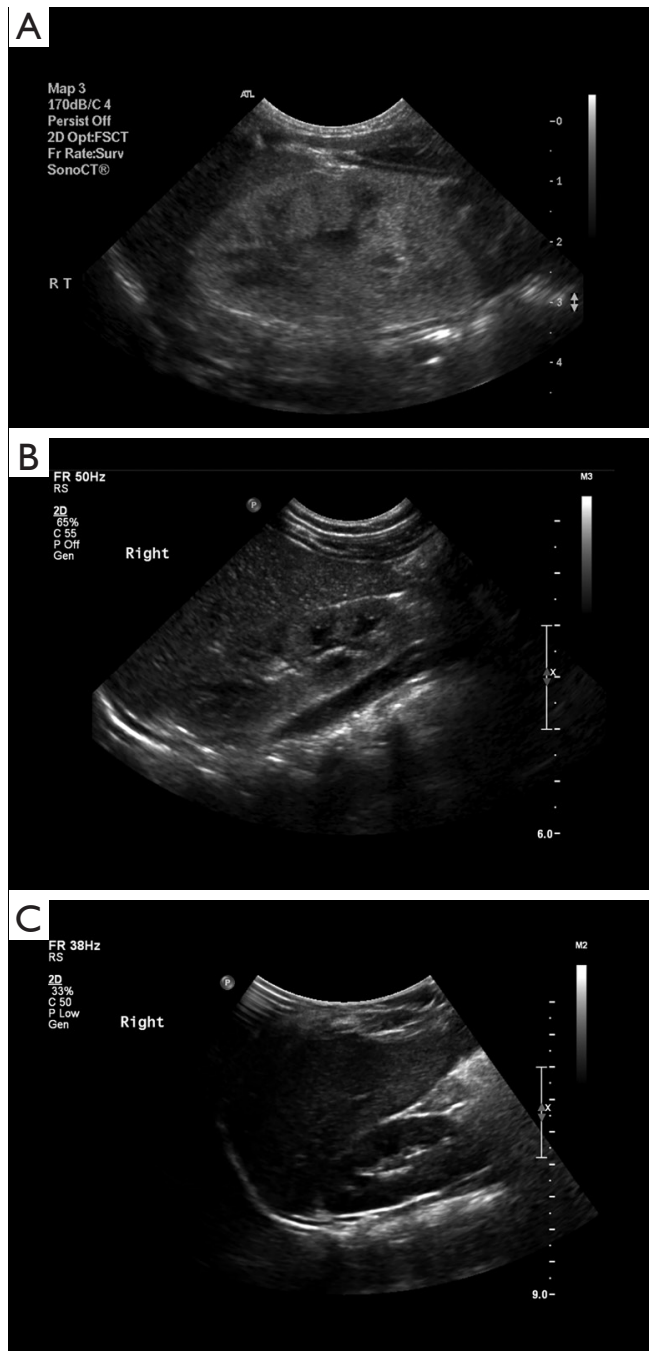

Figure 1 Patient 1: gradual normalization of renal parenchymal hyperechogenicity on ultrasound performed at ages: (A) 1 month, (B) 5 months and (C) 1.5 years.

$1.4 \mathrm{mg} \%$; normal lab range $1.8-2.5 \mathrm{mg} \%$ ), slightly elevated uric acid: $5.8 \mathrm{mg} \%$ normal up to $5.6 \mathrm{mg} \%$ ), and slightly elevated ALT (48 IU/L; normal <35 IU/L). The serum creatinine, thyroid, and parathyroid test results were normal. Her urinalysis was normal, but she was found to have magnesuria (FEMg 7-10\%; normal $<5 \%$, and $<2-4 \%$ with a depressed serum magnesium level: $<1.8 \mathrm{mg} \%$ ) (23) without hypercalciuria. A renal ultrasound showed normalsize kidneys (7.4-7.6 cm long axis) (24), with normal echogenicity. An electroencephalogram demonstrated rolandic-type epileptic activity.

Past medical history was relevant for fetal hyperechogenic kidneys, with normal amniotic fluid volume and without any other sonographic abnormalities. Amniocentesis was performed for maternal age of 36 years and the karyotyping results were normal. After an uneventful elective cesarean section delivery at gestational week (GW 38) with a birth weight of 2,600 gr, borderline small hyperechogenic kidneys (4.2-4.4 cm long axis) were detected on ultrasound. The serum creatinine level was elevated: $0.98 \mathrm{mg} / \mathrm{dL}$; normal range for age up to $0.8 \mathrm{mg} / \mathrm{dL}$ (25). Normalization of serum creatinine was observed by ages 1.5 and 18 months (0.4 and $0.3 \mathrm{mg} / \mathrm{dL}$, respectively), and complete resolution of parenchymal hyperechogenicity with normal kidney growth was demonstrated on ultrasound at the age of 24 months. Figure 1A-1C displays the gradual sonographic normalization of kidney appearance.

This patient's family history was positive for the mother's 2 non-recurrent seizure episodes at age 22 years, epilepsy diagnosed in one of her cousins, and autistic spectrum disorder (ASD) in another cousin. There was no known familial kidney disease. Antiepileptic therapy instituted for recurrent focal seizures and myoclonic jerks together with magnesium supplement achieved complete seizure control. CMA performed for evaluation of hypomagnesemia revealed the typical $17 \mathrm{q} 12[34,815,551-36,275,773]$ deletion of $\sim 1.46 \mathrm{Mb}$ encompassing the $H N F I B$ gene.

Currently, at 6 years of age, the child is in excellent general condition and is developing normally although she is overweight [body mass index (BMI) $>95$ th percentile for age]. Her blood pressure is normal as is her renal function: the last serum creatinine (enzymatic) level was $0.34 \mathrm{mg} \%$-eGFR $=180 \mathrm{~mL} / \mathrm{min}$ (Schwartz formula) (25), with borderlineto-low serum magnesium (1.6-1.8 $\mathrm{mg} \%)$ on daily oral magnesium supplement. Serum uric acid, cholesterol and PTH levels were slightly elevated: $5.8 \mathrm{mg} \%, 230 \mathrm{mg} \%$ and $76 \mathrm{pg} / \mathrm{mL}$ (upper normal range: $5.5 \mathrm{mg} \%, 199 \mathrm{mg} \%$ and $66 \mathrm{pg} / \mathrm{mL}$, respectively). Normal-size kidneys: $8.1-8.4 \mathrm{~cm}$ length (24) with normal parenchymal echogenicity were demonstrated on ultrasound.

\section{Patient 2}

Patient 2 was the fetus of a 34-year-old primipara woman who was referred to pediatric nephrology consultation for fetal bilateral hyperechogenic low-normal-size kidneys (10-25th percentile length) and normal amniotic fluid volume, without any other abnormal findings on fetal ultrasound at GW 32. A fetal magnetic resonance imaging (MRI) study revealed focal cystic changes in a small left kidney (32.8 $\mathrm{mm}$ length, 5 th percentile) and a bilateral 
irregular kidney contour with a hyperintense rim. The 30-year-old father reported diabetes onset at age 18 years, and his renal ultrasound performed upon our request revealed borderline small kidneys that measured $10 \mathrm{~cm}$ in length (his height was $178 \mathrm{~cm}$ ), with normal renal function.

Amniocentesis (at GW 32) had revealed a normal male karyotype, but CMA analysis demonstrated a $\sim 1.5 \mathrm{Mb}$ deletion at $17 \mathrm{q} 12$ chromosome $[34,822,465-36,410,720]$ encompassing the $H N F 1 B$ gene. The father was found to harbor a similar $17 \mathrm{q} 12$ deletion. Pregnancy was terminated on parental request because of the possibility of renal and severe neurodevelopmental outcome consequent to the genetic diagnosis. The parents declined a post-mortem examination of the aborted fetus.

\section{Patient 3}

Patient 3 was a full-term (GW 41) normal male baby, birth weight $3,100 \mathrm{gr}$, who was born after a normal pregnancy. Bilateral enlarged (75-90th percentile long axis) hyperechogenic kidneys and normal/slightly increased amniotic fluid volume had been detected at the beginning of the second trimester. No extrarenal abnormalities were found. The family history was negative for cystic kidney disease, and the parental ultrasound performed on the nephrology consultant's request was normal. The parents declined amniocentesis. A fetal MRI at GW 32 confirmed enlarged kidneys: 49-51 mm length (>97th percentile) (4) with bilateral cystic changes and normal amniotic fluid volume. The post-delivery physical examination was normal (including blood pressure), without dysmorphic features or respiratory distress. A neonatal renal ultrasound confirmed large hyperechogenic kidneys (5-5.5 cm long axis) (23), with small (up to $4 \mathrm{~mm}$ ) cortical cysts and mild right hydronephrosis [anteroposterior renal pelvic diameter (APRPD) 9-10 mm]. The initially elevated serum creatinine of $1 \mathrm{mg} \%$ (normal $0.8 \mathrm{mg} \%$ ) (25) dropped to the normal range for age $(0.3 \mathrm{mg} \%)$ by age 1.5 months. Molecular analysis at age 2 years (delayed since birth by parental choice) revealed a $1.38 \mathrm{Mb}$ deletion at $17 \mathrm{q} 12[34,815,551-36,195,082]$ encompassing the $H N F 1 B$ gene. The parents declined further genetic tests for themselves or their other children.

The first febrile Enterococcus faecalis urinary tract infection (UTI) was diagnosed at the age of 3.5 years. Bilateral hydroureteronephrosis and incomplete bladder emptying were found on ultrasound, and subsequent voiding cystourethrography showed bilateral moderate-to-severe vesicoureteral reflux (grades 3 and 4 on the left and right, respectively), with 2 bladder diverticula and normal urethra.
Bilateral ureteral reimplantation and resection of the bladder diverticula were performed, with no recurrent UTI.

The child's physical and neurocognitive development are currently normal at age 6 years. He is slightly overweight (BMI $>85$ th percentile for age), and he has normal blood pressure. His kidney function is normal (eGFR $134 \mathrm{~mL} / \mathrm{min}$ ), with depressed serum magnesium (1.6 mg\%). Several episodes of elevated fasting serum glucose $(108 \mathrm{mg} \%)$ were recorded with complete normalization on follow-up. An abdominal ultrasound showed persistently large kidneys ( $>95$ th percentile length for age) (24), with multiple small cysts but no cystic involvement in any other abdominal organs.

\section{Patients 4 and 5}

Patients 4 and 5 were discordant monochorionic female twins whose birth weights were 1,680 and 2,070 gr, respectively. They were born by cesarean section at GW 34.5 due to preterm labor. During pregnancy, bilateral hyperechogenic kidneys were suspected on fetal ultrasound, more apparent in the smaller twin. A fetal MRI at GW 32 showed that the smaller twin had a moderately hydronephrotic (APRPD $=11 \mathrm{~mm})$ normal-size right kidney (50th percentile for $\mathrm{GW}$ ), with thinned ( $2-3 \mathrm{~mm}$ width) renal parenchyma and abnormal signal and a normal-texture small left kidney (3rd percentile for GW) (4). The size of the larger twin's kidneys was normal (25th percentile for GW) and they had a slightly abnormal parenchymal signal, although less pronounced than those of her sister. The amniotic fluid volume was normal for both twins. There was no history of familial kidney disease, and both parents had normal findings on their kidney ultrasound studies. Amniocentesis was not performed. The post-delivery physical examination, including blood pressure, was normal for both twins. Kidney ultrasonography at age nine days revealed bilateral hyperechogenic kidney lengths of 44-45 (normal) and 34-38 mm (small) in the larger and smaller twins, respectively. Slightly elevated serum creatinine levels at age 2 days (1.1 and $1.09 \mathrm{mg} \%$, respectively), decreased to the upper normal range $(0.64-0.76 \mathrm{mg} \%)$ at discharge at age 19 days (24). The pediatric nephrology followup that continued for the ensuing 36 months revealed normal physical growth of both twins: 50th and 85 th height percentile for corrected age, with normal blood pressure, renal function (eGFR $145 \mathrm{~mL} / \mathrm{min}$ Schwarz formula) (25), serum creatinine levels $(0.35-0.37 \mathrm{mg} \%)$, and urinalysis. Liver enzymes were slightly elevated: ALT $=45-68$ IU/L (normal range up to $35 \mathrm{IU} / \mathrm{L}$ ) and GGT=114 IU/L 

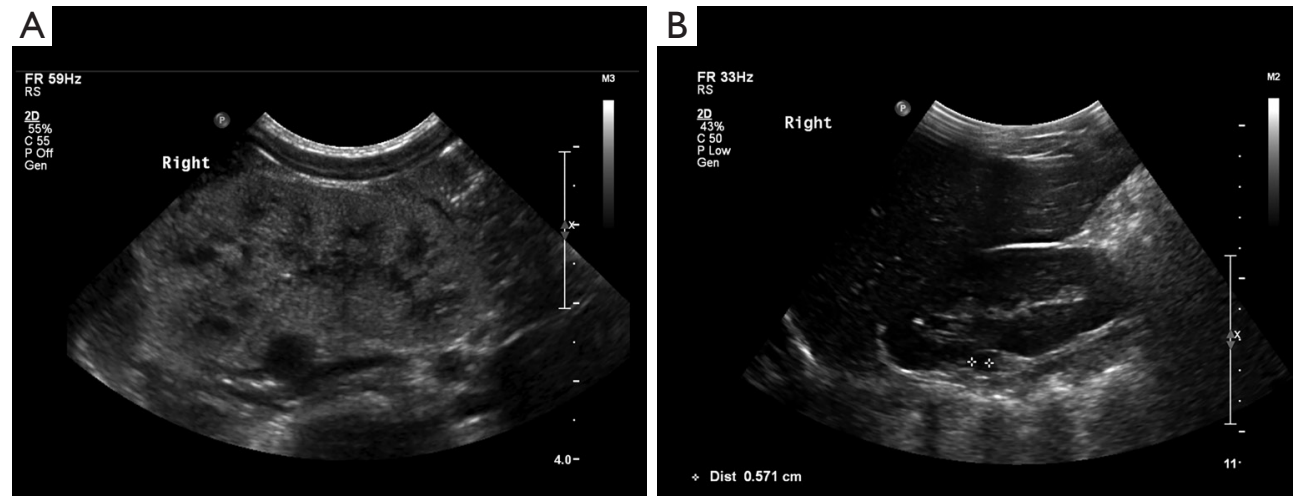

Figure 2 Patient 6: normalization of renal parenchymal hyperechogenicity on ultrasound between age (A) 1 month and (B) 4.9 years with residual small cyst in solitary functioning right kidney.

(normal range up to $37 \mathrm{IU} / \mathrm{L}$ ). Kidney hyperechogenicity as demonstrated on ultrasound resolved completely by age 3 years, and kidney size was within the lower normal range (62-68 mm length) for both twins (24).

By the age of 2 years, neurodevelopmental assessment of both twins showed global severe developmental delay (mental developmental index $=52$ and 49 , for the larger and smaller twin, respectively), and they both met the criteria for autism spectrum disorder according to DSM-V. On molecular analysis performed in the clinical context CMA detected a $17 \mathrm{q} 12[34,816,551-36,383,538]$ deletion of $1.57 \mathrm{Mb}$ encompassing the gene $H N F 1 B$, and a $1 \mathrm{q} 43$ deletion of $58 \mathrm{~Kb}$ including the RYR2 gene. No 17q12 microdeletion was reported on the parents' CMA, while a 1q43 deletion was detected and found to be maternally inherited.

\section{Patient 6}

Patient 6 was a 11.5 -year-old girl who has been followed in the pediatric nephrology clinic since birth for suspected left MCDK on fetal ultrasound and neonatal elevated serum creatinine: $1.7 \mathrm{mg} \%$ (25). She was born at GW 38 with a birth weight of 3,100 gr. A fetal ultrasound had diagnosed left MCDK with a normal right kidney and normal amniotic fluid volume at GW 22. Amniocentesis had shown a normal female karyotype. Neonatal examination was normal (including blood pressure), with no dysmorphic features. A patent foramen ovale was found on an echocardiogram, and the brain ultrasound was normal. An abdominal ultrasound at this age was consistent with left MCDK and an enlarged right hyperechogenic kidney with small cortical cysts, the largest of which was $4 \mathrm{~mm}$ diameter. Serum creatinine normalized gradually by the age of 8 months
(0.3 $\mathrm{mg} \%$ ) (25), while the right kidney hyperechogenicity subsided gradually to two residual upper pole cysts $(7 \mathrm{~mm}$ maximal size) and complete resolution of the left MCDK by the age of 4.9 years. Interestingly, a DMSA renal scan at the age of 2 months showed a solitary functioning right kidney with homogenous isotope uptake. Figure $2 A, 2 B$ shows normalization of the sonographic appearance of the right solitary functioning kidney.

Currently, at age 11.5 years, the patient is a normal, welldeveloped youngster (height $157.5 \mathrm{~cm}=85$ th percentile) with normal blood pressure and normal kidney function: eGFR $151-147 \mathrm{~mL} / \mathrm{min}$ (serum creatinine $0.53 \mathrm{mg} \%$ ) with a low magnesium level (1.37 $\mathrm{mg} \%$ ) due to magnesuria, and a uric acid level in the upper normal range $(5.8 \mathrm{mg} \%)$. The urinalysis findings were normal. A CMA analysis performed for evaluation of hypomagnesemia (which was difficult to control) and persistent solitary kidney cystic changes revealed a pathogenic mutation at the locus of the $H N F 1 B$ gene consisting of a $\sim 1.6 \mathrm{Mb}$ deletion at $17 \mathrm{q} 12[34,822,465-$ $36,404,555]$. The girl's parents have not yet completed the recommended CMA.

\section{Discussion}

The most common presentation of $H N F 1 B$-related disease consists of either fetal bilateral (sometimes asymmetrical) hyperechogenic kidneys with variable amniotic fluid volume or overt CAKUT with MCDK comprising $25 \%$ of these cases detected pre- or postnatally $(10,12,13,15-21)$. The most intriguing and novel finding in our study is the unexpected postnatal complete sonographic resolution of renal parenchymal hyperechogenicity, without evolution 
to cystic changes among unsuspected prenatal cases. This contrasts with the inevitable cystic deterioration described by others $(10,17,20)$. This normalization was observed within $24-57$ months in 4 of our patients, with very limited local persistence of cystic changes in one of them. Moreover, normalization of initially abnormal renal function was even more rapid, having been observed within 2-8 months. As expected, the longest interval to normalization was monitored in the patient with the solitary functioning kidney. This observation contrasts with reports of a $23-61 \%$ rate of impaired renal function recovery in similar cases within 1 month to 14 years $(10,12,13,15-17)$, and also with the predicted worse renal outcome of early presentation of $H N F 1 B$-associated kidney abnormalities (10). Importantly, we found no correlation between the persistent diffuse cystic changes observed since the fetal MRI in one patient with the completely normal renal function during 6 years of close follow-up (Patient 3). While no consistent genotypephenotype correlation has been reported for either the renal or the extrarenal phenotype (13-15), the better renal function prognosis in our cohort with all patients harboring the same deletion type mutation might represent the counterpart of the worse outcome reported in one study for point mutation/truncating intragenic mutations (17). Our finding is also consistent with reports of a very low rate $(12.8 \%)$ of progression to end-stage renal disease during childhood as well as thereafter $(13,16,26)$.

We postulate that the cause underlying the spontaneous resolution of the initial abnormalities might be compensatory changes in the adjacent normal renal parenchyma. Similarly, the complete normalization of initially depressed renal function observed in our cohort is remarkable and supports this hypothesis. Larger prospective studies should be undertaken for better delineation of $H N F 1 B$ mutation-associated renal prognosis.

Another novel finding among our patients is the coexistence of both types of $H N F 1 B$-associated kidney abnormalities, i.e., cystic kidneys and CAKUT, which presented sequentially in Patient 3. The great majority of $H N F 1 B$ mutation cohorts, including the most recently reported ones, described the renal cystic/dysplastic changes as the most prominent imaging feature of this mutation. While HNF1B mutation is recognized as one of the most commonly identified genetic causes of CAKUT, the simultaneous occurrence of these two expressions of the same mutation was very rarely reported: specifically, once in a post-mortem study of aborted fetuses (18) and in two cases described in two recently reported cohorts of 67 (27) and
33 patients (28) carrying the mutation. It is critically important to pursue the diagnosis of possible CAKUT as suggested by evolving uromechanical abnormalities (hydronephrosis, hydroureter) on serial ultrasound examinations in the context of cystic kidneys due to HNF1B with the aim of preventing secondary kidney damage associated with UTI.

Neurodevelopmental involvement is one of the most feared extrarenal features of a $H N F 1 B$ deletion. The twins of the current cohort were diagnosed with ASD, which reportedly occurs at a 9- to 18 -fold higher rate in association with $17 \mathrm{q} 12$ microdeletion than in the general population (13-16,29-31). Increased prevalences of other psychiatric disorders, intellectual disability, and learning problems were also reported in association with the $17 \mathrm{q} 12$ microdeletion $(13,14,29,32)$. Seizure disorder has only rarely been reported in $17 \mathrm{q} 12$ microdeletions (33). The rolandictype seizures in our Patient 1, who is neurodevelopmentally intact, could have represented a mere coincidental finding in a family in which seizures are known to have affected the mother and a maternal aunt. However, the reported autism in the maternal aunt is intriguing, and we speculate that it might be another feature of an undetected $H N F 1 B$ deletion.

Additional $H N F 1 B$-associated extrarenal features, such as hypomagnesemia, hyperuricemia, elevated liver enzymes, and abnormal parathyroid hormone levels, which have been reported in up to $44 \%$ of these cases $(13,15,16,23)$, were also observed in our cohort. Worth emphasizing is the finding of hypomagnesemia with magnesuria, which was the sign that triggered genetic diagnosis in two of our patients (Patients 1 and 6). This often overlooked sign has a later onset in patients who carry the mutation and might reflect ongoing tubulointerstitial renal involvement $(13,16)$. Also, the elevated BMI in two of our patients (Patients 1 and 3) and the upper normal range of fasting blood glucose in one of them (Patient 3) might suggest a predisposition for lateronset DM due to the pancreatic hypoplasia that is inherent to this syndrome $(15,18)$.

Specific criteria have recently been defined for initiating a HNF1B mutation search in patients with CAKUT $(2,21,26)$. The findings in our cohort highlight additional clinical and laboratory cues that should prompt a molecular diagnosis search for $H N F 1 B$ mutations in those patients. These signs include a history of fetal hyperechogenic kidneys with complete postnatal resolution or fetal-onset cystic kidneys (possibly revealed by fetal MRI in cases of unclear sonographic findings) not congruent with the recognized pattern of ADPKD or ARPKD, or fetal 
diagnosis of MCDK with an abnormal/cystic contralateral kidney-all of these with normal renal function (possibly after an initial mild-moderate abnormality). A relevant family history of diabetes, gout, fertility problems, or autism should be sought along with asymptomatic CAKUT on parental kidney ultrasound. These clues along with the recognized $30-40 \%$ rate of inherited heterozygous $H N F 1 B$ microdeletions $(10,13-17,21)$ highlight the importance of molecular diagnosis, despite the slowly evolving phenotypic features and the intrafamilial variability, as exemplified by the paternal phenotype of our Patient 2 (the aborted fetus). On the other hand, the detection of a $17 \mathrm{q} 12$ deletion in children evaluated for developmental delay or ASD should prompt a thorough nephrological and metabolic evaluation as well as continued follow-up until adulthood and thereafter.

The main limitation of our study is the very small size of our cohort.

In conclusion, our series adds several novel features to the highly variable, multifaceted, and perpetually evolving spectrum of $H N F 1 B$ mutations. Early molecular diagnosis will dictate long-term multidisciplinary follow-up in these patients for best management of any associated renal and multisystemic $H N F 1 B$ mutation features.

\section{Acknowledgments}

The paper was edited by Ms. Esther Eshkol, the institutional native English-language medical copyeditor. Funding: None.

\section{Footnote}

Reporting Checklist: The authors have completed the STROBE reporting checklist. Available at https://dx.doi. org/10.21037/tp-21-386

Data Sharing Statement: Available at https://dx.doi. org/10.21037/tp-21-386

Peer Review File: Available at https://dx.doi.org/10.21037/ tp-21-386

Conflicts of Interest: All authors have completed the ICMJE uniform disclosure form (available at https://dx.doi. org/10.21037/tp-21-386). The authors have no conflicts of interest to declare.
Ethical Statement: The authors are accountable for all aspects of the work in ensuring that questions related to the accuracy or integrity of any part of the work are appropriately investigated and resolved. The study was conducted in accordance with the Declaration of Helsinki (as revised in 2013). The study was approved by the Institutional Ethics Review Board of Tel Aviv Sourasky Medical Center Ichilov Hospital (registration No. 0498-14TLV) and individual consent for this retrospective analysis was waived.

Open Access Statement: This is an Open Access article distributed in accordance with the Creative Commons Attribution-NonCommercial-NoDerivs 4.0 International License (CC BY-NC-ND 4.0), which permits the noncommercial replication and distribution of the article with the strict proviso that no changes or edits are made and the original work is properly cited (including links to both the formal publication through the relevant DOI and the license). See: https://creativecommons.org/licenses/by-nc-nd/4.0/.

\section{References}

1. Rasmussen M, Olsen MS, Sunde L, et al. Kidney anomalies diagnosed by prenatal ultrasound screening and associated non-urinary malformations: a nationwide prevalence study. Prenat Diagn 2016;36:847-53.

2. Sanna-Cherchi S, Westland R, Ghiggeri GM, et al. Genetic basis of human congenital anomalies of the kidney and urinary tract. J Clin Invest 2018;128:4-15.

3. Nicolaou N, Renkema KY, Bongers EM, et al. Genetic, environmental, and epigenetic factors involved in CAKUT. Nat Rev Nephrol 2015;11:720-31.

4. Dias T, Sairam S, Kumarasiri S. Ultrasound diagnosis of fetal renal abnormalities. Best Pract Res Clin Obstet Gynaecol 2014;28:403-15.

5. Gimpel C, Avni FE, Bergmann C, et al. Perinatal Diagnosis, Management, and Follow-up of Cystic Renal Diseases: A Clinical Practice Recommendation With Systematic Literature Reviews. JAMA Pediatr 2018;172:74-86.

6. Chaumoitre K, Brun M, Cassart M, et al. Differential diagnosis of fetal hyperechogenic cystic kidneys unrelated to renal tract anomalies: A multicenter study. Ultrasound Obstet Gynecol 2006;28:911-7.

7. Goodyer P, Gupta IR. Renal Dysplasia/Hypoplasia. In: Avner ED, Harmon WE, Niaudet P, et al. editors. 
Pediatric Nephrology. 7th edition. Berlin: Springer, 2016:115-34.

8. Weber S, Moriniere V, Knüppel T, et al. Prevalence of mutations in renal developmental genes in children with renal hypodysplasia: results of the ESCAPE study. J Am Soc Nephrol 2006;17:2864-70.

9. Vivante A, Hildebrandt F. Exploring the genetic basis of early-onset chronic kidney disease. Nat Rev Nephrol 2016;12:133-46.

10. Uy N, Reidy K. Developmental Genetics and Congenital Anomalies of the Kidney and Urinary Tract. J Pediatr Genet 2016;5:51-60.

11. Decramer S, Parant O, Beaufils S, et al. Anomalies of the TCF2 gene are the main cause of fetal bilateral hyperechogenic kidneys. J Am Soc Nephrol 2007;18:923-33.

12. Thomas R, Sanna-Cherchi S, Warady BA, et al. HNF1B and PAX2 mutations are a common cause of renal hypodysplasia in the CKiD cohort. Pediatr Nephrol 2011;26:897-903.

13. Clissold RL, Hamilton AJ, Hattersley AT, et al. HNF1Bassociated renal and extra-renal disease-an expanding clinical spectrum. Nat Rev Nephrol 2015;11:102-12.

14. Mitchel MW, Moreno-De-Luca D, Myers SM, et al. 17q12 Recurrent Deletion Syndrome 1993.

15. Verhave JC, Bech AP, Wetzels JF, et al. Hepatocyte Nuclear Factor 1 $\beta$-Associated Kidney Disease: More than Renal Cysts and Diabetes. J Am Soc Nephrol 2016;27:345-53.

16. Bockenhauer D, Jaureguiberry G. HNF1B-associated clinical phenotypes: the kidney and beyond. Pediatr Nephrol 2016;31:707-14.

17. Heidet L, Decramer S, Pawtowski A, et al. Spectrum of HNF1B mutations in a large cohort of patients who harbor renal diseases. Clin J Am Soc Nephrol 2010;5:1079-90.

18. Duval H, Michel-Calemard L, Gonzales M, et al. Fetal anomalies associated with HNF1B mutations: report of 20 autopsy cases. Prenat Diagn 2016;36:744-51.

19. Madariaga L, Morinière V, Jeanpierre C, et al. Severe prenatal renal anomalies associated with mutations in HNF1B or PAX2 genes. Clin J Am Soc Nephrol 2013;8:1179-87.

20. Jones GE, Mousa HA, Rowley H, et al. Should we offer prenatal testing for $17 \mathrm{q} 12$ microdeletion syndrome to all cases with prenatally diagnosed echogenic kidneys?
Prenatal findings in two families with $17 \mathrm{q} 12$ microdeletion syndrome and review of the literature. Prenat Diagn 2015;35:1336-41.

21. Raaijmakers A, Corveleyn A, Devriendt K, et al. Criteria for HNF1B analysis in patients with congenital abnormalities of kidney and urinary tract. Nephrol Dial Transplant 2015;30:835-42.

22. Loewen J, Greenbaum LA. Diagnostic imaging of the child with suspected renal disease. In: Avner ED, Harmon WE, Niaudet P, et al. editors. Pediatric Nephrology. 7th edition. Berlin: Springer, 2016:667-704.

23. Viering DHHM, de Baaij JHF, Walsh SB, et al. Genetic causes of hypomagnesemia, a clinical overview. Pediatr Nephrol 2017;32:1123-35.

24. Rosenbaum DM, Korngold E, Teele RL. Sonographic assessment of renal length in normal children. AJR Am J Roentgenol 1984;142:467-9.

25. van der Watt G, Omar F, Brink A, et al. Laboratory investigation of the child with suspected renal disease. In: Avner ED, Harmon WE, Niaudet P, et al. editors. Pediatric Nephrology. 7th edition. Berlin: Springer, 2016:613-36.

26. Faguer S, Chassaing N, Bandin F, et al. The HNF1B score is a simple tool to select patients for HNF1B gene analysis. Kidney Int 2014;86:1007-15.

27. Okorn C, Goertz A, Vester U, et al. HNF1B nephropathy has a slow-progressive phenotype in childhood-with the exception of very early onset cases: results of the German Multicenter HNF1B Childhood Registry. Pediatr Nephrol 2019;34:1065-75.

28. Nagano C, Morisada N, Nozu K, et al. Clinical characteristics of HNF1B-related disorders in a Japanese population. Clin Exp Nephrol 2019;23:1119-29.

29. Clissold RL, Shaw-Smith C, Turnpenny P, et al. Chromosome $17 \mathrm{q} 12$ microdeletions but not intragenic HNF1B mutations link developmental kidney disease and psychiatric disorder. Kidney Int 2016;90:203-11.

30. Loirat C, Bellanné-Chantelot C, Husson I, et al. Autism in three patients with cystic or hyperechogenic kidneys and chromosome 17q12 deletion. Nephrol Dial Transplant 2010;25:3430-3.

31. Gilboa Y, Perlman S, Pode-Shakked N, et al. Prenatal diagnosis of $17 \mathrm{q} 12$ deletion syndrome: from fetal hyperechogenic kidneys to high risk for autism. Prenat Diagn 2016;36:1027-32.

32. Laffargue F, Bourthoumieu S, Llanas B, et al. Towards 
a new point of view on the phenotype of patients with a 17q12 microdeletion syndrome. Arch Dis Child 2015;100:259-64.

Cite this article as: Cleper R, Reches A, Shapira D, Simchoni S, Reisman L, Ben-Sira L, Yaron Y, Wolman I, Malinger G, Brabbing-Goldstein D, Ben-Shachar S. Improving renal phenotype and evolving extra-renal features of $17 \mathrm{q} 12$ deletion encompassing the $H N F 1 B$ gene. Transl Pediatr 2021;10(12):3130-3139. doi: 10.21037/tp-21-386
33. Nagamani SC, Erez A, Shen J, et al. Clinical spectrum associated with recurrent genomic rearrangements in chromosome 17q12. Eur J Hum Genet 2010;18:278-84. 